\title{
Nonlinear Effect between Diversification and Corporate Performance from the Perspective of TMT Faultlines: A Panel Smooth Transition Model
}

\author{
Jiebin Zhou \\ School of Business Administration, South China University of Technology, Guangzhou, China \\ Email: jiebin_zhou@163.com
}

How to cite this paper: Zhou, J.B. (2018) Nonlinear Effect between Diversification and Corporate Performance from the Perspective of TMT Faultlines: A Panel Smooth Transition Model. American Journal of Industrial and Business Management, 8, 174-192. https://doi.org/10.4236/ajibm.2018.81012

Received: December 20, 2017

Accepted: January 26, 2018

Published: January 29, 2018

Copyright $\odot 2018$ by author and Scientific Research Publishing Inc. This work is licensed under the Creative Commons Attribution International License (CC BY 4.0).

http://creativecommons.org/licenses/by/4.0/

\begin{abstract}
The results of existing researches of the relationship of diversification-performance are unstable and contradictory. Hence, according to the theory of TMT faultlines, this empirical study utilizes a panel smooth transition (PSTR) model to investigate whether the relationship of diversification-performance will have a nonlinear transition due to TMT faultlines. Evidence from a sample of 95 publicly traded companies in China from 2006-2015 shows a nonlinear effect under the influence of task-related faultlines and bio-demographic faultlines. Specifically, when transition variable is task-related faultlines, the threshold divides the PSTR model into two regimes with the values of 0.2262 . The effect on the relationship transforms from insignificant negative correlation to positive correlation as the model transforms from low regime to high regime. When it comes to bio-demographic faultlines, the threshold divides it into three regimes with the values of 0.1602 and 0.7146 . The effect becomes negative in the crowding-out regimes but turns to a positive correlation in the middle regime. Therefore, the main contribution of this study is that it not only offers a new way of thinking for answering the arguments of the relationship, but also provides a basis for decision making when choosing the senior management team for the implementation of diversification strategy.
\end{abstract}

\section{Keywords}

Task-Related Faultlines, Bio-Demographic Faultlines, Diversification, Corporate Performance, Panel Smooth Transition Model 


\section{Introduction}

Since the US strategy researchers put forward the theory of diversification in the 1950s, the relationship of diversification-performance has long been a mainstay of strategic management research (Chatterjee and Wernerfelt, 1991; Christensen and Montgomery, 1981) [1] [2]. However, the academic field has not yet reached a consensus about the relationship of diversification-performance. In order to discuss the relationship between the diversification and performance deeply, this study uses PSTR model to explore the nonlinear effect on the relationship of diversification-performance under the influence of TMT faultlines.

Compared with the existing researches, this study has the following contributions. Firstly, this study utilizes the recently developed panel smooth transition regression (PSTR) model with a continuous 10 years panel data to analyze the nonlinear relationship of diversification-performance in a diversified operational environment. Secondly, from the perspective of TMT faultlines, based on Hutzschenreuter research (Hutzschenreuter et al., 2013) [3], this study chooses taskrelated faultlines and bio-demographic as transition variables. Thus, it is helpful to overcome the shortage of static indicator brought from team heterogeneity and enriches TMT faultlines research in TMT cognition theory. Meanwhile, there are still few empirical researches about diversification and TMT faultines. Therefore, this study can provide a brand-new perspective for the research into the relationship of diversification-performance.

\section{Literature Review}

Many scholars have conducted an discussion of the relationship base on the theory of resource-based view (RBV), holding the opinions that diversified operation corporates can make full use of resources and abilities among different operation units, such as, specialized human capitals (Farjoun, 1998) [4], managerial know-how (Prahalad and Bettis, 1986) [5] or technological know-how (Robins and Wiersema, 1995) [6]. Moreover, it can promote the realization of economies of scope and reduction of transaction costs (Teece, 1980) [7]. However, the principal-agent theory suggests that the separation between ownership and control right of modern corporates will lead to disagreement of interests and information asymmetry between the manager and the owner, and turn to overinvestment problems and agency costs (Stulz, 1990; Jensen and Meckling, 1976) [8] [9]. All these may play a role in declining corporate performance. Unlike strategy scholars, industrial economic scholars universally recognize the existence of "diversification discount," pointing out that diversified operation corporate can impose a negative influence on corporate performance. Comment and Jarrel (1995) found that the decrease of diversification level could efficiently increase the return rate of corporate stocks [10]. Berger and Ofek (1995) analyzed financial data of 3600 corporates during 1986-1991 [11]. Their findings showed that, due to the influence of cross-subsidization and overinvestment, diversification brought about $13 \%-15 \%$ of value losses on average. In addition, as 
the complex interaction and mechanism between diversification and corporate performance, Palich, Cardinal and Miller (2000) thought that there might be a nonlinear effect on the relationship of diversification-performance [12]. They adopted the meta-analysis to analyze 55 existing relevant literatures, finding out there was an inverted-U-shaped relationship between diversification and corporate performance. In other words, performance brought by diversification was better than that based on single business operation and irrelevant diversification.

The existing findings show that there are three varied relationships, namely positive correlation, negative correlation and inverted-U-shaped correlation. Based on the above argument, some scholars think that organizational fit is a key factor for efficient implementation of diversification (Haspeslagh and Jemison, 1991; Jemison and Sitkin, 1986) [13] [14]. In other words, whether diversification strategy can achieve the desired goals depends on the coordination between the external social environment and the internal organizational conditions ( $\mathrm{Pa}$ lich, Cardinal and Miller, 2000; Wan et al., 2011) [12] [15]. Top management team (TMT), as a core group of corporate strategy decision-making, not only directly influences corporate performance, but also indirectly influences corporate performance by their strategy decision-making behaviors and implementation process (Finkelstein and Hambrick, 1990) [16]. Besides, TMT plays an important role in coordinating internal organizational conditions and external social environment ( $\mathrm{Su}$ and Tsang, 2015) [17]. Therefore, it is necessary to consider TMT as an important factor on the relationship of diversification-performance. Currently, the scholars have achieved fruitful findings about the relationship among the diversification strategy, TMT and corporate performance. Based on the upper echelons theory, they argue that demographics characteristic, such as age, educational experiences, working experiences and tenure, of TMT members are a "mirror" of TMT traits, reflecting TMT values, special experiences and personality. They can affect TMT members' judgment of the external environment and ultimately influence strategic actions adopted by corporates and corporate performance (Finkelstein and Hambrick, 1990) [16]. However, the single static demographics characteristic, which usually uses TMT heterogeneity as its indicator, ignores multiple demographics and their dynamic synergetic effects of TMT members (Lau and Murnighan, 1998) [18]. Nor can they reflect the dynamic process generate by interaction of TMT members. As a result, the "the black box of organizational demography" is formed (Lawrence, 1997) [19]. In recent years, the concept of "demographic faultlines" put forward by Lau and Murnighan (1998) has gained increasing attention from the academic field because it can replace the team heterogeneity single demographic indicator with the dynamic polymerized team member multiple demographics to make up for the existing shortage of team heterogeneity [18]. The concept has investigated the effect of multiple demographic characteristics within team members on team performance, strategic decision and corporate performance (Knippenberg et al., 2011) [20]. Meanwhile, Hutzschenreuter and Horstkotte (2013) divided TMT faultlines into task-related faultlines and bio-demographic faultlines, and pointed out 
its influence on corporate expansion strategy [3]. Thus, this study adopts the TMT faultlines to stand for the changes of TMT characteristic, which is more accurate to reflect the moderate effect of TMT on the diversification strategy decision-making and makes the study be more scientific and precise.

Corporates implementing diversification strategy are just a dynamically developing system. The correlation among its various systems is not causal relationship or the fixed proportion while it often reflected as a nonlinear feedback (Zhang, 2006) [21]. The relationship of diversification-performance may generate a nonlinear effect due to different intensity of TMT faultlines when diversified corporates are in the dynamic development environment. However, the existing researches concentrate more on analyzing the relationship with the simple linear regression model, ignoring that the relationship is also a dynamically developing process. Besides, both diversification and corporate performance are constrained by the time, so it had better consider the longitudinal time in order to make the relationship clear (Lubatkin and Chatterjee, 1991) [1]. Nevertheless, the existing researches just collect the diversification and corporate performance data just for certain year, which is not persuasive in time series. It also explains why the previous empirical researches come to inconsistent conclusions in terms of research methodologies (Hoskisson and Hitt, 1992) [22].

\section{Model Set up and Data}

\subsection{Panel Smooth Transition Regression Model}

The PSTR model of Gonzales et al. (2005) [23], which is the expansion of panel threshold regression (PTR) model, not only effectively portrays cross-section heterogeneous changes of panel data, but also allows model parameters to change in a smooth, nonlinear manner as the transition variables change. A PSTR model with a transition variable defined as:

$$
y_{i t}=\mu_{i}+\beta_{0}^{\prime} x_{i t}+\beta_{1}^{\prime} x_{i t} g\left(q_{i t} ; \gamma, c\right)+\varepsilon_{i t}
$$

for $i=[1, N]$ and $t=[1, T]$, where $N$ and $T$ respectively represent the cross-section and time dimensions of the panel. The dependent variable $y_{i t}$ is a scalar; explanatory variable $x_{i t}$ is a k-dimensional column vector; while $\mu_{i}$ refers to the fixed effect; and $\varepsilon_{i t}$ is the residual. The parameters $\beta_{0}$ and $\beta_{1}$ are respectively represent the linear part and nonlinear part of the PSTR model. The transition function $g\left(q_{i t} ; \gamma, c\right)$ is the bounded continuous function of the transition variable $q_{i t}$ and is normalized to be bounded between 0 and 1 . More generally, transition function $g\left(q_{i t} ; \gamma, c\right)$ determines the nonlinear effect. Slope parameter $\gamma$ determines the smoothness of the transitions; location parameter $c$ determines the location of the dynamic transition. The widely used transition function is a logistic specification as in Formula (2).

$$
g\left(q_{i t} ; \gamma, c\right)=\left(1+\exp \left(-\gamma \prod_{j=1}^{m}\left(q_{i t}-c_{j}\right)\right)\right)^{-1}
$$

For the value of $\mathrm{m}$ in the transition function $g\left(q_{i t} ; \gamma, c\right)$, Terasvirta (1994) 
proposed that it is sufficient to consider $m=1$ or $m=2$. When $m=1$, the transition function $g\left(q_{i t} ; \gamma, c\right)$ is logistic, and it is a two extreme regimes model which consists of a transition function [24]. Moreover, for $q_{i t} \rightarrow-\infty$, the limit of $g\left(q_{i t} ; \gamma, c\right)$ is equal to 0 , and the corresponding Formula (1) is called the low regime; for $q_{i t} \rightarrow+\infty$, the limit of $g\left(q_{i t} ; \gamma, c\right)$ is equal to 1 , and it is called the high regime. As the value of the transition function changes smoothly between 0 and 1 , the model (1) changes smoothly between the high and low regimes at transition point $c$. The corresponding explanatory variable coefficient also changes between $\beta_{0}$ and $\beta_{0}+\beta_{1}$ as $q_{i t}$ increases, where taking $\mathrm{c}$ as the center. When $m=2$, the transition function $g\left(q_{i t} ; \gamma, c\right)$ is indexical, and it is divided into a three-regime threshold model which contains two crowding-out regimes and one middle regime. The transition function obtains its minimum at $q_{i t}=\left(c_{1}+c_{2}\right) / 2$, and the model (1) is in the middle regime. For $q_{i t} \rightarrow \pm \infty$, it attains the value 1 in two crowding-out regimes. Therefore, the most obvious characteristic of the PSTR model is that dependent variable $y_{i t}$ will have a smooth transition in different mechanisms with the change of the panel unit $i$ and $t$.

\subsection{Construction of PSTR Model}

The early research on diversification-performance relationship based on the linear model ignored the internal structure change of each variable. What's more, it was difficult to reflect the dynamic development of the variable and this may finally result in the deviation of the objective phenomenon and research findings. Considering the diversification strategy is a dynamically developing system, the linear model cannot effectively portray its characteristic as well as accurately reflect the relationship of diversification-performance. Therefore, this study uses the PSTR model to make an in-depth analysis of the relationship of diversification-performance and investigate whether the relationship will exhibit nonlinear transition in response to changes in the strength of top management team faultlines.

There have some factors, which will have an impact on the implementation of the corporate diversification strategy. Thus, according to the existing research, this study chooses to use corporate age (CAGE), the total number of corporate shares (TNS), the ratio of state-owned shares (STA), discretional power (DP) and debt ratio (DEBT) as control variables and uses the diversification strategy (DIV) as explanatory variables. Considering the above factors, this study utilizes PSTR model to explore the relationship of diversification-performance under the influence of the transition variables, including task-related faultlines and bio-demographic faultlines. Therefore, based on model (1), the complete PSTR model of the task-related faultlines and the bio-demographic faultlines as the transition variables shows that the nonlinear effect between diversification strategy and corporate performance is as follows:

$$
\begin{gathered}
R O E_{i t}=\mu_{i}+\beta_{0} x_{i t}+\beta_{1} x_{i t} g\left(T_{R F} ; \gamma, c\right)+\varepsilon_{i t} \\
R O E_{i t}=\mu_{i}+\beta_{0} x_{i t}+\beta_{1} x_{i t} g\left(B D F_{i t} ; \gamma, c\right)+\varepsilon_{i t}
\end{gathered}
$$


where: $x_{i t}$ represents the explanatory variables (diversification strategy) and control variables (corporate age, total number of corporate shares, ratio of stateowned shares, discretional power and debt ratio).

\subsection{Sample Selection}

To explore the nonlinear effect between the relationship of diversification-performance under the effect of task-related faultlines and bio-demographic faultlines, the publicly traded A shares on the Shanghai and Shenzhen exchanges are selected as the sample of corporates of this study. Due to the speed of database updating and the difficulty of data collecting, we only used the panel data during the period 2006-2015. This study filters the samples as follows:

Firstly, this study screens out the continuous operation listed corporate during the period 2006-2015 while excluding financial firms, insurance companies and public utilities because the characteristics of those types of companies would jeopardize the research results. Secondly, we eliminate ST enterprise samples with abnormal financial or other conditions. Thirdly, this study excludes the samples of the mergers, asset reorganization and special treatment. Finally, incomplete data sets of corporates' main business data and executive disclosure data are also excluded.

Ultimately, this study acquires a balanced panel data set with the number of cross-sections $N=95$ and the time series $T=10$ for 950 valid observed values. All date used in this study were collected from CSMAR database. In addition, to ensure data accuracy and completeness, the data obtained from CSMAR database were verified using data from the annual reports of the listed companies and SINA Finance.

\subsection{Definition of Variables}

\section{Dependent variable}

Corporate Performance The main indicators of measuring corporate performance, including return on common stockholders' equity (ROE), return on total assets ratio (ROA), earnings per share (EPS) and Tobin's $\mathrm{Q}$, has its own advantage in the assessment and evaluation of corporate performance. This study finally chooses the ROE as the main indicator of the corporate performance based on the reason that ROE is more likely to depict the corporate goals of the maximization of shareholders' value and it highlights the overall ability of corporate operation.

\section{Explanatory variable}

Diversification The measuring indicator of the degree of diversification varies in existing literature. Rumelt (1974) proposed the proportion of indicators of vertical and horizontal integration [25]; Jacquemin and Berry (1974) [26] suggested the use of the diversification entropy coefficient while other researchers prefer to use Herfindahl index (Herfindahl, 1950; Hill, Hit and Hoskisson, 1992) [27] [28]. As the diversification entropy coefficient can measure accurately and 
contain large information about diversification, thus, this study selects the diversification entropy coefficient as the measure of the degree of diversification. In addition, this study employs the method of Yao et al. (2004) [29] of measuring the degree of diversification by using Standard Industrial Classification (SIC) codes to calculate the entropy coefficient and the formula is:

$$
\mathrm{DIV}=\sum_{i=1}^{n} P_{i} \ln \left(1 / P_{i}\right)
$$

This study uses the 4-digit SIC system to define industry categories. $P_{i}$ refers to the ratio of the sales revenue of $I^{\text {th }}$ industry to the corporate's total sales, $\mathrm{n}$ is the number of industries in a corporate's business portfolio and $\ln \left(1 / P_{i}\right)$ represents the weight of the $i^{\text {th }}$ industry. The higher the value of DIV is, the higher the degree of diversification is.

\section{Transition variables}

TMT Faultlines More strategy scholars have focused more attention on the TMT faultlines because it investigates the interaction of team members and reflects the dynamic polymerization of TMT characteristic, which has a strong explanation for the impact of TMT characteristic and can overcome the divergence between theoretical expectations and empirical findings from the configuration perspective. This study employs $\mathrm{Fau}_{g}$ indicator proposed by Thatcher et al. (2003) to measure the TMT faultlines [30]. Specifically, for the measure of the transition variables of task-related faultlines and bio-demographic faultlines, this study considers the task-related characteristic (tenures and education level) and bio-demographic characteristic (ages and gender) as the main indicators. The calculation formula of TMT Faultlines is as follows:

$$
\text { Fau }_{g}=\frac{\sum_{j=1}^{q} \sum_{k=1}^{2} n_{k}^{g}\left(\bar{x}_{j k}-\bar{x}_{j}\right)^{2}}{\sum_{j=1}^{q} \sum_{k=1}^{2} \sum_{i=1}^{n_{k}^{g}}\left(x_{i j k}-\bar{x}_{j}\right)^{2}}, g=1,2, \cdots, S
$$

where: $q$ represents the number of the TMT member characteristic; $\bar{x}_{j}$ denotes the overall TMT mean of characteristic $j ; \bar{x}_{j k}$ represents the mean of characteristic $j ; x_{i j k}$ refers to the value of the $f^{\text {th }}$ characteristic of the $i^{\text {th }}$ member of subgroup k and $n_{k}^{g}$ is the number of TMT members of the $k^{\text {th }}(k=1,2)$ under split $g(g=1,2, \cdots, S)$.

As a team faultline can divide the group into two subgroups in a total of $S=2^{n-1}-1$ ways, Thatcher et al. (2003) suggested that it is less likely for the group to be divided into three or more subgroups and the calculation is more complex. Therefore, this study only considers the condition of TMT group divided into two subgroups. When comes to the definition of TMT, it varies in existing research. Hambrick et al. (1996) proposed that TMT consisted of vicepresident and the above titles [31] Elron (1998) defined TMT as senior management, including CEO and senior vice presidents [32]. According to the definition and measure of the TMT faultlines, this study limits the TMT of chairman (vice), CEO (vice), executive manager (vice), and secretary of the board of directors and others who have a power for corporate management and decision-making. This study also determines the TMT group sizes of $3-10$ persons 
to simplify the calculation process.

Since the calculation of $\mathrm{Fau}_{g}$ is based on the Euclidean distance, special treatment should be taken when involved with both continuous and categorical variables. Specifically, for these variables can combine with Euclidean distance, this study recodes the categorical variables (ages and gender) into a series of dummy variables and then rescales the continuous variables (tenures and education level) and the dummy variables. The following action is found out the maximum value of $\mathrm{Fau}_{g}$ as the final TMT faultlines strength in a total of $S=2^{n-1}-1$ ways. We use R2010b Matlab software to complete the calculation process.

\section{Control variable}

On the basis of the existing research method (Krishnan, Miller and Judge, 1997; Chakrabarti, Singh and Mahmood, 2007) [33] [34], corporate age (CAGE), total number of corporate shares (TNS), ratio of state-owned shares (STA), discretional power (DP) and debt ratio (DEBT) are selected as control variables. Corporate age is calculated by the observed year minus the foundation year. Total number of corporate shares is measured by a natural logarithm of total number of corporate issued shares. The ratio of state-owned shares is calculated by dividing the number of state-owned shares by the total number of corporate shares. Moreover, discretional power refers to the shareholding ratio of senior management members and debt ratio is total debt divided by total assets.

The descriptive statistics of the sample are demonstrated from Table 1. It is obvious that corporate has a mean value of $7.13 \%$ while standard deviation is $11.32 \%$, illustrating that there are a little difference in corporate performance among the samples corporates. The maximum value of diversification is 1.31 , the minimum is 0 and the mean value is 0.25 , showing that the sample corporates have a low level of diversification and are not willing to carry out the diversification strategy. The value for task-related faultlines and bio-demographic faultlines is 0.27 and 0.31 . The TMT faultline strength in sample corporates is generally low.

Table 1. Descriptive statistics results.

\begin{tabular}{cccccc}
\hline Variable & Mean & Median & S.D. & Maximum & Minimum \\
\hline ROE (\%) & 7.13 & 6.59 & 11.32 & 61.79 & -95.53 \\
DIV & 0.25 & 0.13 & 0.28 & 1.31 & 0 \\
TRF & 0.27 & 0.23 & 0.14 & 0.75 & 0 \\
BDF & 0.31 & 0.28 & 0.12 & 1 & 0.11 \\
CAGE & 11.41 & 11 & 3.43 & 22 & 5 \\
TNS & 19.99 & 19.90 & 0.78 & 22.76 & 18.50 \\
STA & 0.25 & 0.22 & 0.25 & 0.76 & 0 \\
ZS & 0.0002 & 0 & 0.0011 & 0.02 & 0 \\
DEBT & 0.48 & 0.50 & 0.18 & 0.86 & 0.06 \\
\hline
\end{tabular}

Sources: Statistical analysis of R2010b Matlab; samples: $T=10, N=95$. 


\section{Empirical Results and Analysis}

\subsection{Nonlinear Existence Test}

This study first need to determine whether there is a nonlinear effect on the relationship of diversification-performance. Consequently, it assumes that the null hypothesis is $\mathrm{H}_{0}: \gamma=0$ or $\mathrm{H}_{0}: \beta_{1}=0$ and then test the null hypothesis. However, the PSTR model still contains unidentified nuisance parameters under both of these hypotheses. Thus, this study follows the study of Luukkonen et al. (1988) [35] to allow the transition function $g\left(q_{i t} ; \gamma, c\right)$ to be replaced by its first-order Taylor expression around $\gamma=0$, so that it turns to the following auxiliary regression model: $y_{i t}=\mu_{i t}+\beta_{0} x_{i t}+\beta_{1} x_{i t} q_{i t}+\epsilon_{i t}$. In addition, we constructs the likelihood ratio test (LRT) (t-distribution) based on the auxiliary regression model. If the results reject the null hypothesis, which means that there is at least one transition function $g\left(q_{i t} ; \gamma, c\right)$ in the PSTR model, the nonlinear effect indeed exist on the relationship of diversification-performance.

In summary, this study uses task-related faultlines and bio-demographic faultlines as the transition variables and examines the LRT test. The results are presented in Table 2. The LRT statistics for TRF and BDF are separately 48.657 and 29.021; both reject the null hypothesis at a significance level of $1 \%$, showing that the relationship of diversification-performance will have a nonlinear smooth transition under the influence of task-related faultlines and bio-demographic faultlines.

\subsection{Determination of the Value of $M$}

After examining the nonlinear existence test of PSTR model, this study then uses the theory proposed by Hansen (1996) [36], Gonzalez, and Terasvirta (2005) [23] to determine the value of $\mathrm{m}$ in the transition function $g\left(q_{i t} ; \gamma, c\right)$. Therefore, this study conducts a first-order Taylor expansion to the model (1) when $\gamma$ $=0$ and sets up the three test hypotheses to determine the final value of $m: \mathrm{H}_{03}$ : $\beta_{3}=0 ; \mathrm{H}_{02}: \beta_{2}=0 \mid \beta_{3}=0$ and $\mathrm{H}_{01}: \beta_{1}=0 \mid \beta_{2}=\beta_{3}=0$. We then examine these null hypotheses by $\mathrm{F}$-value and if the rejection of $\mathrm{H}_{02}$ is the strongest one, $m=2$ is used; otherwise, $m=1$ is used according to the strongest rejection principle. The results are presented in Table 3.

This study finally chooses $m=1$ as the value of $m$ in the transition function $g\left(T R F_{i t} ; \gamma, c\right)$ and $m=2$ as the value of $m$ in the transition function $g\left(B D F_{i t} ; \gamma, c\right)$. From this, we can know that transition function $g\left(T R F_{i t} ; \gamma, c\right)$ is related to

Table 2. Nonlinear existence test.

\begin{tabular}{ccc}
\hline & $\mathrm{H}_{0}: \beta_{0}=\beta_{1}=\beta_{2}=\cdots=\beta_{\mathrm{i}}=0$ & \\
\hline TRF & BDF \\
\hline LRT Tests (LRT) & $48.657^{* * *}$ & $29.021^{* * *}$ \\
$P$-value & 0.000 & 0.000 \\
\hline
\end{tabular}

Note: Significance levels: ${ }^{\star * *} p<0.01,{ }^{* \star} p<0.05,{ }^{\star} p<0.1$, two-tailed tests. 
Table 3. Determination of the value of $M$.

\begin{tabular}{ccc}
\hline When the rejection of $\mathrm{H}_{02}$ is the strongest, select $\mathrm{m}=2$; otherwise select $\mathrm{m}=1$ \\
\hline $\mathrm{H}_{03}: \beta_{3}=0$ & 0.292 & $\mathrm{BDF}$ \\
$\mathrm{H}_{02}: \beta_{2}=0 \mid \beta_{3}=0$ & 0.958 & 0.187 \\
$\mathrm{H}_{01}: \beta_{1}=0 \mid \beta_{2}=\beta_{3}=0$ & 1.180 & 0.836 \\
\hline
\end{tabular}

Note: Significance levels: ${ }^{* *} p<0.01,{ }^{* *} p<0.05,{ }^{\star} p<0.1$, two-tailed tests.

transition variable $T R F_{i t}$ and shows a monotonic increase. Model (3) is split into low and high regimes. On the other hand, transition function $g\left(B D F_{i t} ; \gamma, c\right)$ divide model (4) into two crowding-out regimes and one middle regime and generate a nonlinear symmetric variation at the point of $B D F_{i t}=\left(c_{1}+c_{2}\right) / 2$.

\subsection{Parameter Estimation}

According to the nonlinear effect of the PSTR model and the value of $\mathrm{m}$, we use Simulate Anneal Arithmetic to estimate the model parameter and carry out the calculation by R2010b Matlab. Table 4 shows the results of parameter estimation when transition variables are TRF and BDF. The empirical results demonstrate that the model (3) is divided into high and low regimes with threshold value $c=$ 0.2262 and transition slope $\gamma=21.6018$. This indicates the model (3) occurs a nonlinear smooth transition when TRF $=0.2262$. Table 4 also shows that the model (4) is divided into two crowding-out regimes and one middle regime with threshold value of $c_{1}=0.1602$ and $c_{2}=0.7146$, and transition slope $\gamma=16.6691$. This indicates the model (4) occurs a nonlinear symmetric variation when BDF $=(0.1602+0.7146) / 2=0.4374$. Therefore, based on the results in Table 4 , when transition variables are TRF and BDF, the two complete PSTR models show that the nonlinear effect on the relationship of diversification-performance are as follows:

$$
\begin{aligned}
& R O E_{i t}=\mu_{i}+\beta_{0} x_{i t}+\beta_{1} x_{i t} g\left(T R F_{i t} ; 21.6018,0.2262\right)+\varepsilon_{i t} \\
& \beta_{0}=(-0.0024,0.0161,-0.0012,0.0171,-0.4522,-0.0215) \\
& \beta_{1}=(0.0062,-0.0171,0.0020,-0.0225,1.2093,0.0158) \\
& R O E_{i t}=\mu_{i}+\beta_{0} x_{i t}+\beta_{1} x_{i t} g\left(B D F_{i t} ; 16.6691,0.1602\right) \\
& +\beta_{1} x_{i t} g\left(B D F_{i t} ; 16.6691,0.7146\right)+\varepsilon_{i t} \\
& \beta_{0}=(0.0125,-0.0010,0.0001,-0.0058,1.1139,0.0090) \\
& \beta_{1}=(-0.0363,0.0245,-0.0010,0.0343,-3.1951,-0.0712) \\
& x_{i t}=\left(C A G E_{i t}, T N S_{i t}, S T A_{i t}, Z S_{i t}, D E B T_{i t}, D I V_{i t}\right)
\end{aligned}
$$

\subsection{Empirical Analysis}

1) TRF as the transition variable

Obviously, the smooth transition mechanism has the stage characteristics of linear and nonlinear. We can learn from Table 4 that the threshold value of 
Table 4. PSTR model parameter estimation result.

\begin{tabular}{ccccc}
\hline \multirow{2}{*}{ Variable } & \multicolumn{2}{c}{ Transition variable is TRF } & \multicolumn{2}{c}{ Transition variable is BDF } \\
\cline { 2 - 5 } & $\beta_{0}$ & $\beta_{1}$ & $\beta_{0}$ & $\beta_{1}$ \\
\hline \multirow{2}{*}{ DIV } & -0.0024 & $0.0062^{*}$ & $0.0125^{* * *}$ & $-0.0363^{* * *}$ \\
& $(-0.7881)$ & $(1.7794)$ & $(3.0663)$ & $(-3.1534)$ \\
CAGE & $0.0161^{* * *}$ & $-0.0171^{\star * *}$ & -0.0010 & 0.0245 \\
& $(5.0764)$ & $(-3.8341)$ & $(-0.1848)$ & $(1.5295)$ \\
TNS & -0.0012 & $0.0020^{* * *}$ & 0.0001 & -0.0010 \\
& $(-1.2260)$ & $(3.5869)$ & $(0.0927)$ & $(-0.5080)$ \\
STA & $0.0171^{* * *}$ & $-0.0225^{* * *}$ & -0.0058 & $0.0343^{*}$ \\
& $(4.5638)$ & $(-3.9558)$ & $(-0.9717)$ & $(1.8286)$ \\
ZS & -0.4522 & 1.2093 & 1.1139 & -3.1951 \\
& $(-0.7946)$ & $(0.5533)$ & $(0.7709)$ & $(-0.8179)$ \\
DEBT & $-0.0215^{* * *}$ & $0.0158^{* *}$ & 0.0090 & $-0.0712^{* * *}$ \\
& $(-3.1161)$ & $(2.0392)$ & $(1.1082)$ & $(-2.8510)$ \\
Location parameter C & \multicolumn{2}{c}{0.2262} & $\mathrm{c}_{1}=0.1602 ; \mathrm{c}_{2}=0.7146$ \\
Transition slope $\gamma$ & \multicolumn{2}{c}{16.6691} \\
\hline
\end{tabular}

Note: Significance levels: ${ }^{* *} p<0.01,{ }^{* *} p<0.05,{ }^{\star} p<0.1$, two-tailed tests; the corresponding $T$ value is in the brackets.

transition function $g\left(T R F_{i t} ; \gamma, c\right)$ is the location parameter $\mathrm{c}=0.2262$. The results indicate that a structural change occurs in TRF $=0.2262$. Specially, when TRF $<0.2262$ (which task-related faultlines is weak), the linear parameter $\left(\beta_{0}=\right.$ $-0.0024)$ is insignificant and there is an insignificant negative effect on the relationship of diversification-performance. It implies that the increase of task-related faultlines strength will inhibit the positive effect of diversification on corporate performance. When TRF $>0.2262$ (which task-related faultines is strong), its nonlinear parameter $\left(\beta_{1}=-0.0024\right)$ is significantly positive at a significance level of $10 \%$ and there is a significant positive effect $\left(\beta_{0}+\beta_{1}=0.0038\right)$ between diversification and corporate performance. The increase of task-related faultlines strength will promote the positive effect of diversification on corporate performance. In addition, the absolute value of the nonlinear is larger than the linear, which is $\left|\beta_{1}\right|>\left|\beta_{0}\right|$. Therefore, TRF as the transition variable highlights the nonlinear effect on the relationship of diversification-performance, which smoothly translates insignificant negative into positive as the TDF strength enhances and eventually emerge a nonlinear monotonic increase trend.

The graph of the corresponding transition function $g\left(T R F_{i t} ; \gamma, c\right)$ is shown in Figure 1. Specially, when TRF $<0.2262$, the model (6) is in low regime. There are 592 observations, accounting for $62.32 \%$ of all observations. When TRF > 0.2262 , the model (6) is in high regime. There are 358 observations, accounting for $37.68 \%$ of all observations. Based on these results, most observations from the research samples are in the left side of the function $g\left(T R F_{i t} ; \gamma, c\right)$ curve, implying that the strength of TMT task-related faultlines is generally low among the corporates carried out diversification strategy during the period 2006-2015. 


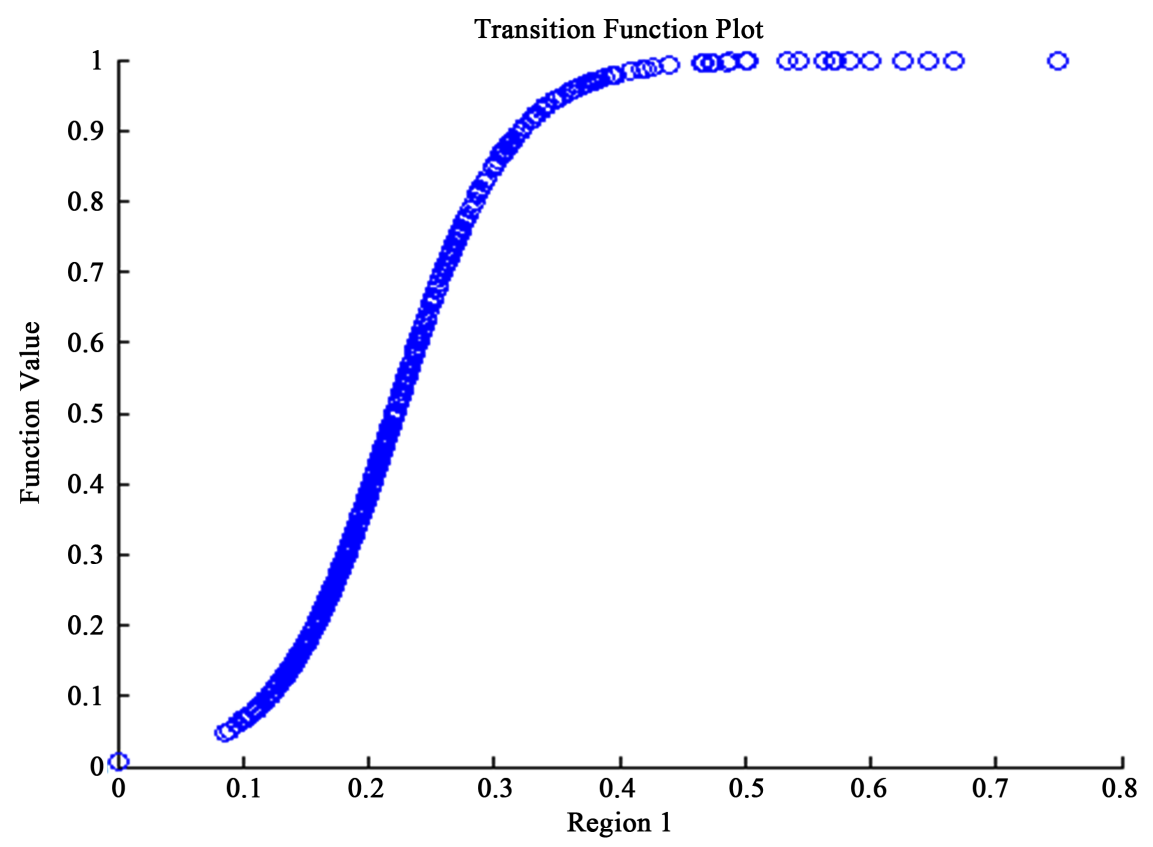

Figure 1. Graph of $g\left(T R F_{i t} ; \gamma, c\right)$.

Thus, it is difficult for TMT members to produce constructive communication and interaction to promptly deal with the uncertainty of the dynamic environment of diversification, to some extent, explaining the reason why most of the diversified corporates in China cannot benefit from diversification strategy.

2) $\mathrm{BDF}$ as the transition variable

The relationship of diversification-performance will exhibit a nonlinear symmetric transition in response to changes in the strength of BDF. We can learn from Table 4 that the linear parameter $\beta_{0}$ equals to 0.0125 and the nonlinear parameter $\beta_{1}$ is -0.0363 . Both of them are significant at the level of $1 \%$ and the absolute value of the nonlinear is larger than linear $\left(\left|\beta_{1}\right|>\left|\beta_{0}\right|\right)$, showing that nonlinear negative effect on the relationship of diversification-performance is stronger than linear positive effect.

The graph of the corresponding transition function $g\left(B D F_{i t} ; \gamma, c\right)$ is shown in Figure 2. The threshold value of transition function $g\left(B D F_{i t} ; \gamma, c\right)$ is the location parameter $c_{1}=0.1602$ and $c_{2}=0.7146$. When BDF is at the range from 0 to 0.1602 or from 0.17145 to infinite, the model (7) is in two crowding-out regimes and the corresponding explanatory variable coefficient is $\beta_{0}+\beta_{1}=$ -0.0238 , in other words, diversification will generate a negative effect on the corporate performance. On the contrary, when BDF is at the range from 0.1602 to 0.7146 , the model (7) in the middle regime and the corresponding explanatory variable coefficient is $\beta_{0}=0.0125$, implying that diversification can promote the improvement of corporate performance. Therefore, as the model (7) transforms from left side crowding-out regime to middle regime and finally to right side crowding-out regime, the relationship of diversification-performance transform from negative effect to positive effect and finally to negative effect. It 


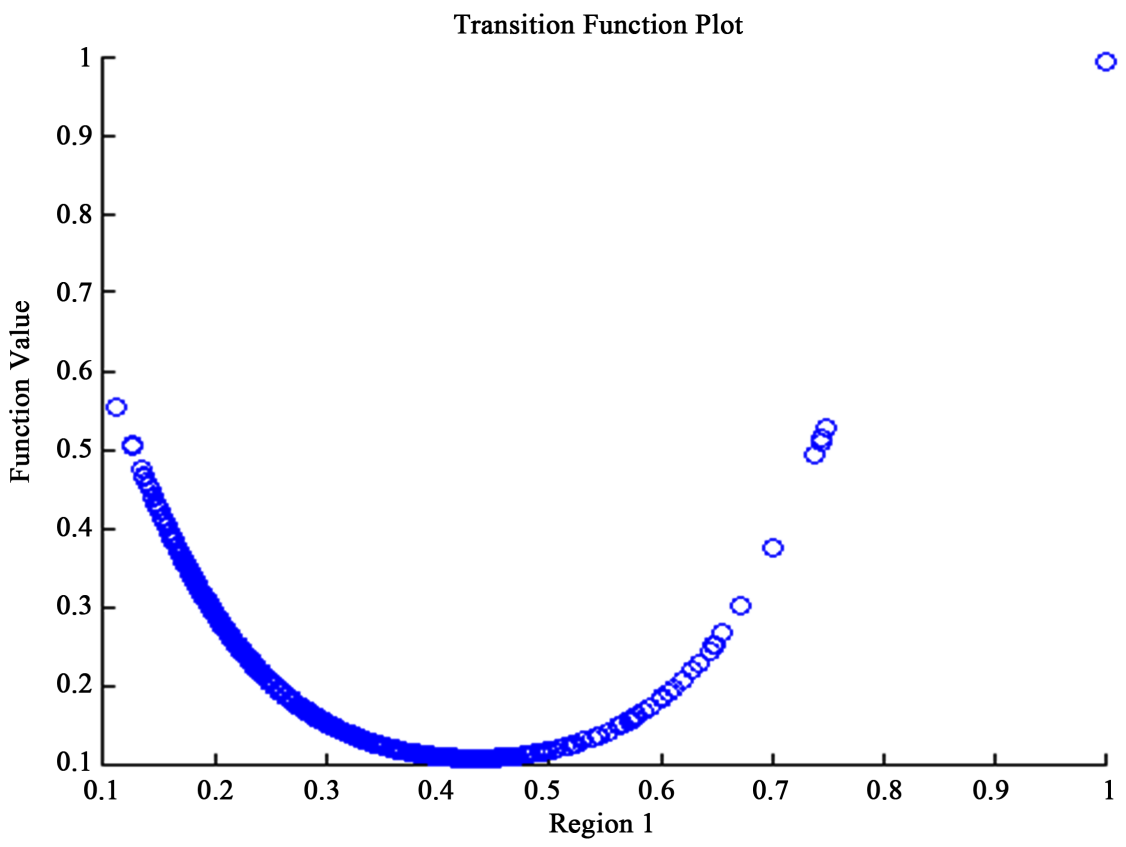

Figure 2. Graph of $g\left(B D F_{i t} ; \gamma, c\right)$.

also implies that the model (7) takes a nonlinear symmetric variation at the center of $\mathrm{BDF}=0.4374$. For the distribution of sample corporates, we found that there are 733 observations, accounting for $77.16 \%$ of all observations when BDF $\leq 0.4374$. On the other hand, there are 217 observations, accounting for $22.84 \%$ when BDF $>0.4374$. These results indicated that most of the observations are gathered on the left side of the U-shaped curve. In summary, most of TMT members have a lower strength of bio-demographic faultlines in the diversified corporates during the period 2006-2015. In addition, too low or too high the strength of bio-demographic faultlines is, the more likely to have an impact on the TMT subgroups' stereotype and emotional reaction and generate conflict and contradiction between TMT members, which will hinder the effective implementation of diversification strategy and turn out to be a negative effect on diversification-performance relationship.

\section{Conclusions}

From the perspective of TMT faultlines, since the linear model ignores the dynamics of corporate diversification strategic, this study adopts the PSTR model to investigate how diversification affects the corporate performance under the influence of task-related faultlines and bio-demographic faultlines. Ultimately, the conclusions of this study are as follows:

There do exist a nonlinear effect between diversification strategy and corporate performance when the transition variables are TMT faultlines, consistent with the conclusions of Palich et al. (2000) [12]. However, the nonlinear effects on the relationship of diversification-performance are different because of the different mechanisms of task-related faultlines and bio-demographic faultlines. 
In particular, the PSTR model is divided into high and low regimes with the threshold value of $\mathrm{TRF}=0.2262$. As the model transforms from low regimes to high regimes, the relationship of diversification-performance is presented by the changing trend of insignificant negative effect to positive effect. While the PSTR model is split into two crowding-out regimes and one middle regime with the threshold value of $\mathrm{BDF}=0.1602$ and $\mathrm{BDF}=0.7146$. Along with the model which transforms from left side crowding-out regime to middle regimes and finally to right side crowding-out regimes, the relationship of diversification-performance is shown by negative effect to positive effect and final conversion to negative effect.

When it comes to task-related faultlines, we find that when TDF exceeds the threshold value $(\mathrm{TRF}=0.2262)$, the increase of the strength of TDF will produce a positive effect on the relationship of diversification-performance. This result is not consistent with social classification theory, which proposed that the greater strength of TDF will promote the generation of kinds of subgroups and it may lead to the disorder of team decision-making (Knippenberg and Schippers, 2007) [37]. In spite of this, we think carrying out diversification strategy means that the corporate has to meet with a greater uncertainty and dynamic environment, putting forward a higher requirement for TMT members' decision-making ability. As TDF is also a kind of useful dividing line (Jehn, Bezrukova and Thatcher, 2008) [38], the greater strength of TDF can provide the necessary knowledge, skills and resources for TMT members to diversification strategy decision-making and it also promotes the communication and interaction with each TMT members aiming at the problems in diversified operation, resulting in the fully sharing and greatly integration of TMT heterogeneous views (Phillips et al., 2004) [39]. Thus, it eventually promotes the effective implementation of diversification strategy and improves the performance of the corporates. Therefore, this study proposes that as the strength of TDF enhances, it can bring more about positive effect than negative effect to diversification strategy and realize the "diversification premium".

When it comes to bio-demographic faultlines, the relationship of diversification-performance has a nonlinear symmetric variation at the center of $\mathrm{BDF}=\left(c_{1}\right.$ $\left.+c_{2}\right) / 2=0.4374$. The results demonstrate that when the PSTR model is in the left side crowding-out regimes or the right side crowding-out regimes, diversification has a negative effect on corporate performance and results in "diversification discount". At the same time, the strength of BDF is at a stage of too high or too low. As BDF is closely related to the relationship conflict and process conflict, too high or too low strength of BDF may cause the relationship conflict and process conflict among team members (Hutzschenreuter and Horstkotte, 2013) [3]. It also hinders TMT members to objectively deal with and evaluate the team internal information and harms the full integration and utilization of TMT members' internal resources and abilities (Jehn, 1995) [40], leading to the sub optimal diversification strategy. Conversely, when the model is in the middle regime, diversification has a positive effect on firm performance, resulting in "di- 
versification premium". At the same time, the strength of BDF is at a stage of proper intensity. It can help the TMT members have the same cognitive ability, learning ability and understanding ability in the diversification strategy decision-making as well as reduce the negative effects caused by relationship conflict and process conflict, which dilutes team members' bias and misunderstanding of other subgroups and their members (Gibson and Vermeulen, 1995) [41]. Finally, TMT members can fully utilize the internal resources and capabilities to deal with the greater uncertainty and do a positive effect on the relationship of diversification-performance.

Therefore, this study not only provides a new perspective to answer the current academic argument about the relationship of diversification-performance, but also use the TMT faultlines theory to investigate the relationship, which is a supplement and enrichment of TMT cognition theory as well as expands the empirical study in the team faultlines. It also provides a practical guidance to corporates that seek to select TMT members who can adapt to diversified strategies. However, because of the measurement of the variables, the sample selection and other reasons, this study has some limitations and it will provide guidance for future in-depth study. Firstly, the measurement of variable of diversification may be not suitable for the actual situation and it would be better for the diversification to subdivide, for example, split it into related diversification and unrelated diversification, especially, the publicly traded companies in China usually adopt related diversification strategy. Therefore, the future research can explore the relationship between related diversification and unrelated diversification, TMT faultlines and corporate performance. Secondly, this study uses task-related faultlines and bio-demographic faultlines as the transition variables. Although it takes corporate interior factors as consideration, like the impact on diversification strategy decision-making from TMT member characteristic, diversification strategy implementation is still constrained by external institutional environment, corporate operation characteristic and other factors. Therefore, future studies may bring external factors into the model, making the model more accurately to portray the complex relationship between diversification and corporate performance.

\section{References}

[1] Lubatkin, M. and Chatterjee. S. (1991) The Strategy-Shareholder Value Relationship: Testing Temporal Stability across Market Cycles. Strategic Management Journal, 12, 251-270. https://doi.org/10.1002/smj.4250120402 http://onlinelibrary.wiley.com/doi/10.1002/smj.4250120402/abstract

[2] Christensen, H.K. and Montgomery, C.A. (1981) Corporate Economic Performance: Diversification Strategy versus Market Structure. Strategic Management Journal, 2, 327-343. http://www.jstor.org/stable/pdf/2486196.pdf https://doi.org/10.1002/smj.4250020402

[3] Hutzschenreuter, T. and Horstkotte, J. (2013) Performance Effects of Top Management Team Demographic Faultlines in the Process of Product Diversification. Strategic Management Journal, 34, 704-726. https://doi.org/10.1002/smj.2035 
http://onlinelibrary.wiley.com/doi/10.1002/smj.2035/pdf

[4] Farjoun, M. (1998) The Independent and Joint Effects of the Skill and Physical Bases of Relatedness in Diversification. Strategic Management Journal, 19, 611-630. http://www.jstor.org/stable/pdf/3094147.pdf https://doi.org/10.1002/(SICI)1097-0266(199807)19:7<611::AID-SMJ962>3.0.CO;2$\underline{E}$

[5] Prahalad, C.K. and Bettis, R.A. (1986) The Dominant Logic: A New Linkage between Diversity and Performance. Strategic Management Journal, 7, 485-501. http://onlinelibrary.wiley.com/doi/10.1002/smj.4250070602/references https://doi.org/10.1002/smj.4250070602

[6] Robins, J.A. and Wiersema, M. (1995) A Resource-Based Approach to the Multibusiness Firm: Empirical Analysis of Portfolio Interrelationships and Corporate Financial Performance. Strategic Management Journal, 16, 277-299.

http://www.jstor.org/stable/pdf/2486958.pdf https://doi.org/10.1002/smj.4250160403

[7] Teece, D.J. (1980) Economies of Scope and the Scope of the Enterprise. Journal of Economic Behavior \& Organization, 1, 223-247.

https://doi.org/10.1016/0167-2681(80)90002-5

http://www.sciencedirect.com/science/article/pii/0167268180900025

[8] Stulz, R.M. (1990) Managerial Discretion and Optimal Financing Policies. Journal of financial Economics, 26, 3-27. https://doi.org/10.1016/0304-405X(90)90011-N http://www.sciencedirect.com/science/article/pii/0304405X9090011N

[9] Jensen, M.C. and Meckling, W.H. (1976) Theory of the Firm: Managerial Behavior, Agency Costs and Ownership Structure. Journal of Financial Economics, 3, 305360. https://www.sfu.ca/ wainwrig/Econ400/jensen-meckling.pdf https://doi.org/10.1016/0304-405X(76)90026-X

[10] Comment, R. and Jarrell, G.A. (1995) Corporate Focus and Stock Returns. Journal of Financial Economics, 37, 67-87. https://doi.org/10.1016/0304-405X(94)00777-X https://econpapers.repec.org/paper/fthrobume/91-01.htm

[11] Berger, P.G. and Ofek, E. (1995) Diversification's Effect on Firm Value. Journal of Financial Economics, 37, 39-65. https://doi.org/10.1016/0304-405X(94)00798-6 https://econpapers.repec.org/article/eeejfinec/v_3a37_3ay_3a1995_3ai_3a1_3ap_3a3 9-65.htm

[12] Palich, L.E., Cardinal, L.B. and Miller, C.C. (2000) Curvilinearity in the Diversification-Performance Linkage: An Examination of over Three Decades of Research. Strategic Management Journal, 21, 155-174.

http://onlinelibrary.wiley.com/doi/10.1002/(SICI)1097-0266(200002)21:2\%3C155:: AID-SMJ82\%3E3.0.CO;2-2/abstract https://doi.org/10.1002/(SICI)1097-0266(200002)21:2<155::AID-SMJ82>3.0.CO;2-2

[13] Haspeslagh, P.C. and Jemison, D.B. (1991) Managing Acquisitions: Creating Value through Corporate Renewal. Free Press, New York. http://www.jstor.org/stable/258765?origin=crossref

[14] Jemison, D.B. and Sitkin, S.B. (1986) Corporate Acquisitions: A Process Perspective. Academy of Management Review, 11, 145-163.

http://amr.aom.org/content/11/1/145.short?relatedurls=yesl11/1/145c11/1/145c11/1 $\underline{/ 145 \mathrm{c} 11 / 1 / 145}$

[15] Wan, W.P., et al. (2010) Resource-Based Theory and Corporate Diversification: Accomplishments and Opportunities. Journal of Management, 37, 1335-1368. http://journals.sagepub.com/doi/abs/10.1177/0149206310391804 
https://doi.org/10.1177/0149206310391804

[16] Finkelstein, S. and Hambrick, D.C. (1990) Top-Management-Team Tenure and Organizational Outcomes: The Moderating Role of Managerial Discretion. Administrative Science Quarterly, 35, 484-503. https://eric.ed.gov/?id=EJ414856 https://doi.org/10.2307/2393314

[17] Su, W. and Tsang, E.W.K. (2015) Product Diversification and Financial Performance: The Moderating Role of Secondary Stakeholders. Academy of Management Journal, 58, 1128-1148. https://doi.org/10.5465/amj.2013.0454 http://amj.aom.org/content/58/4/1128.abstract?cited-by=yesl58/4/1128

[18] Lau, D.C. and Murnighan, J.K. (1998) Demographic Diversity and Faultlines: The Compositional Dynamics of Organizational Groups. Academy of Management Review, 23, 325-340.

http://amr.aom.org/content/23/2/325.abstract?23/2/325r23/2/325c23/2/325r23/2/32 $\underline{5123 / 2 / 325}$

[19] Lawrence, B.S. (1997) Perspective-The Black Box of Organizational Demography. Organization Science, 8, 1-22. https://doi.org/10.1287/orsc.8.1.1

https://pubsonline.informs.org/doi/citedby/10.1287/orsc.8.1.1

[20] Van Knippenberg, D., et al. (2011) Diversity Faultlines, Shared Objectives, and Top Management Team Performance. Human Relations, 64, 307-336.

http://journals.sagepub.com/doi/abs/10.1177/0018726710378384?.journalCode=hu $\underline{\mathrm{ma}}$ https://doi.org/10.1177/0018726710378384

[21] Zhang, P. (2006) Research on Relationship between Top Management Team Heterogeneity and Firm Performance in the Dynamic Competitive Environment. Science and Technology Management Research, 9, 167-170. http://www.cnki.com.cn/Article/CJFDTOTAL-GLSJ200411015.htm

[22] Hill, C.W.L., Hitt, M.A. and Hoskisson, R.E. (1992) Cooperative versus Competitive Structures in Related and Unrelated Diversified Firms. Organization Science, 3, 501-521. https://doi.org/10.1287/orsc.3.4.501 https://pubsonline.informs.org/doi/abs/10.1287/orsc.3.4.501?journalCode=orsc

[23] González, A., Terasvirta, T. and Van Dijk, D. (2005) Panel Smooth Transition Regression Models. School of Finance and Economics, University of Technology. https://econpapers.repec.org/paper/utsrpaper/165.htm

[24] Teräsvita, T. (1994) Specification, Estimation and Evaluation of Smooth Transition Autoregressive Models. Journal of the American Statistical Association, 89, 208-218. http://amstat.tandfonline.com/doi/citedby/10.1080/01621459.1994.10476462

[25] Rumelt, R.P. (1974) Strategy, Structure and Economic Performance. Harvard University Press, Boston, 9-11.

[26] Jacquemin, A.P. and Berry, C.H. (1979) Entropy Measure of Diversification and Corporate Growth. The Journal of Industrial Economics, 27, 359-369. http://www.jstor.org/stable/2097958?origin=crossref https://doi.org/10.2307/2097958

[27] Herfindahl, O.C. (1950) Concentration in the Steel Industry. Columbia University, New York.

[28] Hoskisson, R.E. and Hitt, M.A. (1990) Antecedents and Performance Outcomes of Diversification: A Review and Critique of Theoretical Perspectives. Journal of Management, 16, 461-509. https://doi.org/10.1177/014920639001600210 http://journals.sagepub.com/doi/pdf/10.1177/014920639001600210 
[29] Yao, J., Lu, Y. and Lan, H.L. (2004) An Empirical Study of the Relationship between Diversification and Economic Performance of Listed Companies of China. Management World, No. 11, 119-135. http://www.cnki.com.cn/Article/CJFDTOTAL-KXXG200602024.htm

[30] Thatcher, S.M.B., Jehn, K.A. and Zanutto, E. (2003) Cracks in Diversity Research: The Effects of Diversity Faultlines on Conflict and Performance. Group Decision and Negotiation, 12, 217-241. https://doi.org/10.1023/A:1023325406946 https://link.springer.com/article/10.1023/A:1023325406946

[31] Hambrick, D.C., Cho, T.S. and Chen, M.J. (1996) The Influence of Top Management Team Heterogeneity on Firms' Competitive Moves. Administrative Science Quarterly, 41, 659-684. http://www.jstor.org/stable/2393871? origin=crossref https://doi.org/10.2307/2393871

[32] Elron, E. (1998) Top Management Teams within Multinational Corporations: Effects of Cultural Heterogeneity. The Leadership Quarterly, 8, 393-412.

http://www.sciencedirect.com/science/article/pii/S1048984397900217?via\%3Dihub https://doi.org/10.1016/S1048-9843(97)90021-7

[33] Krishnan, H.A., Miller, A. and Judge, W.Q. (1997) Diversification and Top Management Team Complementarity: Is Performance Improved by Merging Similar or Dissimilar Teams. Strategic Management Journal, 18, 361-374.

http://onlinelibrary.wiley.com/doi/10.1002/(SICI)10970266(199705)18:5\%3C361::A ID-SMJ866\%3E3.0.CO;2-L/abstract https://doi.org/10.1002/(SICI)1097-0266(199705)18:5<361::AID-SMJ866>3.0.CO;2$\underline{\mathrm{L}}$

[34] Chakrabarti, A., Singh, K. and Mahmood, I. (2007) Diversification and Performance: Evidence from East Asian Firm. Strategic Management Journal, 28, 101-120. https://doi.org/10.1002/smj.572

[35] Luukkonen, R., Saikkonen, P. and Teräsvirta, T. (1988) Testing Linearity against Smooth Transition Autoregressive Models. Biometrika, 75, 491-499.

http://www.jstor.org/stable/2336599?origin=crossref https://doi.org/10.1093/biomet/75.3.491

[36] Hansen, B.E. (1996) Inference When a Nuisance Parameter Is Not Identified under the Null Hypothesis. Ecohometrica, 64, 413-430.

http://www.jstor.org/stable/2171789? origin=crossref https://doi.org/10.2307/2171789

[37] Van Knippenberg, D. and Schippers, M.C. (2007) Work Group Diversity. Annual Review of Psychology, 58, 515-541.

https://www.ncbi.nlm.nih.gov/pubmed/16903805/ https://doi.org/10.1146/annurev.psych.58.110405.085546

[38] Jehn, K.A., Bezrukova, K. and Thatcher, S. (2008) Conflict, Diversity, and Faultlines in Workgroups. In: De Dreu, C.K.W. and Gelfand, M.J., Eds., The Organizational Frontiers Series. The Psychology of Conflict and Conflict Management in Organizations, Taylor \& Francis Group/Lawrence Erlbaum Associates, New York, 179-210. https://webpages.scu.edu/ftp/bezrukova/ER9479_C06.pdf

[39] Phillips, K.W., et al. (2004) Diverse Groups and Information Sharing: The Effects of Congruent Ties. Journal of Experimental Social Psychology, 40, 497-510.

http://www.sciencedirect.com/science/article/pii/S0022103103001641 https://doi.org/10.1016/j.jesp.2003.10.003

[40] Jehn, K.A. (1995) A Multimethod Examination of the Benefits and Detriments of Intragroup Conflict. Administrative Science Quarterly, 40, 256-282.

http://www.jstor.org/stable/2393638?origin=crossref 
https://doi.org/10.2307/2393638

[41] Gibson, C. and Vermeulen, F. (2003) A Healthy Divide: Subgroups as a Stimulus for Team Learning Behavior. Administrative Science Quarterly, 48, 202-239.

http://www.jstor.org/stable/3556657? origin=crossref

https://doi.org/10.2307/3556657 